\title{
INFORMATION AND GLOBALIZATION: \\ WAGE CO-MOVEMENTS, LABOR DEMAND ELASTICITY, AND CONVENTIONAL TRADE LIBERALIZATION
}

\author{
James E. Rauch \\ Vitor Trindade \\ Working Paper 7671 \\ http://www.nber.org/papers/w7671 \\ NATIONAL BUREAU OF ECONOMIC RESEARCH \\ 1050 Massachusetts Avenue \\ Cambridge, MA 02138 \\ April 2000
}

Financial support was provided by NSF grant \#SBR-9709237 (Rauch). We thank Alessandra Casella, Mark Machina, Joel Sobel, and Joel Watson for very helpful discussions and Neville Francis and David Ryfe for research assistance. We are also grateful for the comments of participants in seminars at the Santa Cruz International Economics Conference, the University of Washington, Boston College, Dartmouth College, Boston University, Southern Methodist University, and the University of Texas. The views expressed herein are those of the authors and are not necessarily those of the National Bureau of Economic Research.

(C) 2000 by James E. Rauch and Vitor Trindade. All rights reserved. Short sections of text, not to exceed two paragraphs, may be quoted without explicit permission provided that full credit, including (C notice, is given to the source. 
Information and Globalization: Wage Co-Movements, Labor

Demand Elasticity, and Conventional Trade Liberalization

James E. Rauch and Vitor Trindade

NBER Working Paper No. 7671

April 2000

JEL No. F15, F16

\section{$\underline{\text { ABSTRACT }}$}

We model home country familiarity with business opportunities in a foreign country as a parameter in a matching process between domestic and foreign firms. We show that as familiarity increases the effect of relative national labor supplies on relative national wages declines, the elasticity of domestic labor demand increases, and the extent of "pass-through" of trade tax changes to home wages increases. Since the volume of trade is increasing in familiarity, trade liberalization has a greater impact on wages when the initial volume of trade is greater, all else equal. As familiarity becomes complete, the results of the 2 x 2 Heckscher-Ohlin-Samuelson model are obtained: relative national wages are fixed by trade taxes independent of relative national labor supplies, domestic labor demand is infinitely elastic, and pass-through of tax changes to wages is "complete" in the sense that it is determined entirely by production technology and no arbitrage opportunities remain.

James E. Rauch

Department of Economics University of California, San Diego

La Jolla, CA 92093

and NBER

jrauch@weber.ucsd.edu
Vitor Trindade

Department of Economics

University of California, San Diego

La Jolla, CA 92093

vtrindad@weber.ucsd.edu 


\section{Introduction}

The 1990s may well be remembered as the decade "the information economy" came of age. Are businesspeople becoming better informed about opportunities for international trade and foreign direct investment? We do not know of any quantitative evidence that bears directly on this question. Indirect quantitative evidence can be had, however, by counting periodicals and newsletters devoted to international trade and commerce. ${ }^{1}$ We went to three sources: Ulrich's International Periodicals Directory, The Standard Periodical Directory, and Oxbridge Directory of Newsletters, the last two of which cover only U. S. and Canadian publications. In Table 1 we list counts at ten-year intervals starting with 1970 or the first available year. We see that Ulrich's and Standard show a huge leap in growth during the 1990s. Oxbridge shows essentially the same growth during the 1990s as during the 1980s, but growth during the 1980s started from a very small base. The dissemination of periodicals and newsletters has of course been facilitated by developments in information technology during the 1990s, most notably the World Wide Web. These same developments have also advanced the work of government and other nonprofit trade promotion organizations and for-profit trading intermediaries. For example, the World Trade Centers Association, an organization whose "purpose ... is to have information available to businesses in a timely and coordinated manner," now links all of its more than 300 Centers located in over 100 countries through WTCA On-Line.

Though much of the information available in print, through the internet, or from organizations such as the World Trade Centers Association is rather superficial, some is

\footnotetext{
${ }^{1}$ Portes and Rey (1999) have collected two variables, bilateral telephone traffic and bank subsidiaries, that are indirect indicators of familiarity between specific country pairs rather than indicators of generally available information regarding international opportunities. Both of their variables display economically and statistically significant associations with bilateral flows of both equities and goods in gravity models covering 14 countries.
} 
sufficiently in-depth to significantly increase the user's familiarity with trading and investment opportunities in the part of the world being covered. For example, the Asian Industrial Reporter (listed in both Ulrich's and Standard's) covers 'New machinery, equipment, materials and methods for industry in Asia/Pacific countries." If businesspeople are indeed more familiar with international trade and investment opportunities, what are the consequences? In this paper we address the consequences for labor markets in particular.

It has been customary to lump informational barriers to trade together with transportation costs and model both using the "ice" assumption of Samuelson (1954), in which a proportion of the traded good "melts" in transit from one country or region to the other. Informationtransportation costs are then like an ad valorem tariff that generates no revenue; they create a "wedge" up to which international commodity arbitrage is perfect. We take the position that the consequences of increased familiarity with international trade and investment opportunities will be better understood if, instead, informational barriers to trade are modeled as creating an imperfection in the arbitrage process itself, by affecting the extent to which decision makers are in a position to take advantage of arbitrage opportunities.

More specifically, we model a reduction in informational barriers to trade as an increase in familiarity with the set of potential partners in a labor-abundant country with which investors from a labor-scarce country can enter into productive joint ventures. ${ }^{2}$ These joint ventures allow

\footnotetext{
${ }^{2}$ We thus model trade in factor services rather than trade in goods. However, since the latter can be thought of as indirect trade in factor services, we argue in section II that the simplification of dealing with direct factor service trade does not drive our results. We would argue that our specification of factor service trade as occurring through joint ventures is similarly unrestrictive, as it is also appropriate to think of much goods trade as involving joint ventures: producers seek partners to distribute their consumer goods; assemblers seek partners to make components to order. Egan and Mody (1992, p. 325) state of trade in bicycles and footwear, "Most US buyers
} 
investors to arbitrage the difference in wages and consequent difference in production costs that exists between the two countries. Not surprisingly, in our model informational barriers lead to a reduced volume of trade and a "wedge" between the wage rates of the trading partners, and increased familiarity yields increased trade and a decrease in this wedge, just as do reductions in conventional barriers in standard trade models. Our major focus in this paper is on the consequences of increased familiarity that are more surprising, at least in that they do not flow from reductions in conventional barriers (including "ice" transport costs) in standard trade models. In particular, we wish to highlight three sets of results:

- Integration. As familiarity increases, national labor markets become more integrated in the sense that an increase in one country's labor supply has more nearly equal proportionate effects on its wages and those in its trading partner. Wages in the two countries therefore tend to move together more as familiarity increases. A corollary of this result is that as familiarity increases national labor demands become more elastic, an aspect of globalization emphasized by Rodrik (1997).

- Liberalization. As familiarity increases, the extent to which reduction of ad valorem trade taxes (or "ice" transport costs) equalizes relative national wages increases. A corollary of this result is that the extent of "pass-through" of trade tax changes to national wages increases. Since the volume of trade is increasing in familiarity, trade tax changes have a greater impact on wages when the initial volume of trade is greater, all else equal.

- Convergence. As familiarity becomes perfect, our results on integration and

interviewed for this study preferred long-term, stable and direct relationships with both developed and developing country suppliers." 
liberalization converge to those of both the $2 \times 2$ Heckscher-Ohlin-Samuelson model and the standard one-good, two-factor model of trade in factor services to which our model is closer: ${ }^{3}$ relative national wages are determined only by the tax rate (or transport cost) and production technology, hence (1) an increase in the labor endowment of either country affects the wages of both countries equiproportionately, (2) national labor demands are infinitely elastic, and (3) passthrough of tax changes to wages is "complete" in the sense that it is determined entirely by production technology and no arbitrage opportunities remain.

In the next section we motivate our modeling strategy and give the intuition for our major results. The formal model is presented in Section III. In section IV we solve the model and work out its basic comparative statics. Section V contains our results on familiarity and labor market integration, and section VI examines the interaction between familiarity and ad valorem trade barriers. In our concluding section we discuss the implications of our results, and a potential application of our model to issues that arise in the international finance rather than the international trade literature.

\section{Modeling strategy and intuition for main results}

A conventional starting point for analysis of the impact of trade barriers is the $2 \times 2$ Heckscher-Ohlin-Samuelson model. Since we have no reason to expect informational barriers to trade to affect the pattern of trade in commodities any differently than conventional barriers, however, we will take advantage of the simplicity of the standard one-good, two-factor model of

${ }^{3}$ In this respect our model can be seen as a generalization of standard trade models, where the generalization is accomplished by addition of a matching technology. 
international trade in factor services relative to the two-good model and build upon it instead. ${ }^{4}$ In this model the capital abundant country exports capital services to the labor abundant country in exchange for a flow of the numeraire output, rather than exporting capital services embodied in commodities in exchange for labor services embodied in commodities. We wish to show that the one-good and two-good models have the same properties regarding labor-market integration and pass-through of ad valorem trade taxes to wages, so that the results highlighted in the introduction are not driven by use of the simpler model. This is also a good opportunity to review the role of arbitrage in generating these properties.

We first consider the $2 \times 2$ Heckscher-Ohlin-Samuelson model under incomplete specialization in the presence of an ad valorem tariff. ${ }^{5}$ International commodity arbitrage fixes the ratio of the price of the domestic importable to the foreign price at one plus the tariff rate, and the relationship between prices and costs translates the fixed international commodity price ratios (the ratios of each domestic price to its foreign counterpart) into fixed international factor price ratios. A change in one plus the tariff rate changes the relevant international commodity price ratio proportionately, leading to a change in the international wage (and rental) ratio that is determined solely by production technologies. A change in the labor endowment of either country cannot change the international commodity price ratios and therefore cannot change the

\footnotetext{
${ }^{4}$ The use of this model to analyze the impact of trade barriers dates back at least to Becker (1957) and MacDougall (1960).

${ }^{5}$ Complete specialization causes wages measured in terms of domestic output to be independent of the price of foreign output. Hence there is no pass-through of tariff changes to wages and labor markets are completely non-integrated in the sense that a change in foreign labor supply has no impact on the domestic wage measured in terms of domestic output. This result holds regardless of the level of tariffs.
} 
wage ratio, hence the two wages change equiproportionately. Put differently, international commodity arbitrage insures that the proportionate change in relative commodity prices within any country caused by a change in its labor supply is fully transmitted to its trading partner, hence the proportionate changes in factor prices are the same in both countries. Note that this labormarket integration property holds for any non-prohibitive tariff level and thus does not change when the tariff is reduced, unless the tariff is reduced from a prohibitive level.

We now turn to the standard one-good, two-factor model, for which the equivalent of the tariff is a tax on profit earned abroad. Arbitrage now fixes the ratio of the domestic to the foreign capital rental rate at one minus the tax rate, which in turn fixes the international wage ratio. A change in one minus the tax rate changes the international rental ratio proportionately, again leading to a change in the international wage ratio that is determined solely by production technologies. A change in the labor endowment of either country cannot change the international rental ratio and therefore cannot change the wage ratio, hence the two wages change equiproportionately. Again, this labor-market integration property holds for any non-prohibitive tax rate and thus does not change when the tax is reduced unless it is reduced from a prohibitive level.

In our model, informational barriers to trade interfere with the ability to engage in international arbitrage in the following way. Lower wages in the labor abundant country present an opportunity for firms in the labor scarce country. To take advantage of this opportunity, however, a firm must, for example, make a deal with a joint venture partner who knows how to adapt the industry technology to local conditions or with a land developer of a site with access to the appropriate mix of nontraded inputs. Finding a suitable match in an unfamiliar country is 
difficult. In short, we model informational barriers as a matching problem. We feel this general equilibrium specification of uncertainty builds more intuition about the underlying economic mechanisms at work and is closer to the spirit of traditional trade models than a partial equilibrium or ad hoc specification.

We assume that increased familiarity of managers with firms and regional specializations in foreign countries allows producers to rule out more firms and sites in advance (to make a better "first cut") and increases the chances they will find matches that make investments worthwhile for a given wage differential. This ability to respond more effectively to the opportunities presented by wage differentials reduces the extent to which relative wages need to change when labor supplies change in order for national labor markets to clear. In the limit as familiarity becomes complete relative wages do not change at all, just as in the standard models. Like wage differentials, taxes affect the profitability of any given investment. Increased familiarity allows firms to respond more effectively to changes in either of these incentives, thus increasing the labor market impact of changes in profits taxes and increasing the elasticity of national labor demands.

\section{The formal model}

\section{A. Endowments and technology ${ }^{6}$}

The world is composed of two countries, home and foreign. In each country, there is a continuum of types of producers distributed over a circle of unit length. For each type, there is a continuum of producers of unit mass. The producers can therefore be said to lie on a "unit

\footnotetext{
${ }^{6}$ This subsection builds on Rauch and Casella (1998).
} 
cylinder." Each country is also endowed with a homogeneous, inelastically supplied mass of labor. Since there is an equal mass, one, of producers in both countries, the ratio of laborproducer endowment ratios across countries can be summarized by the ratio $L / L^{*}$, where $L$ is the home labor endowment and $L^{*}$ is the foreign labor endowment. In all that follows, asterisks will be used to indicate foreign variables. We assume that the foreign country is the labor-abundant country, so that $L / L^{*}<1$.

Output is generated through a joint venture of two producers, and the distance between their types on the circle is an index of their complementarity or the gains from trade that result from their matching. To actively engage in production, a partnership needs to hire labor; thus output is a function of the quality of the producers' match and the labor employed:

$$
y_{i j}=F\left(x, z_{i j}\right)
$$

where $z_{i j}$ is the shortest arc distance between the two producers of types $i$ and $j$, and $x$ is labor.

Note that the maximum value of $z_{i j}$ is $1 / 2$. The function $F$ is characterized by constant returns to scale. Producers want to maximize profits.

\section{B. Autarky equilibrium}

In autarky, each producer must select a domestic match partner. If his choice does not select him, he gets zero. If his choice does select him, the two producers form a match and bargain over the surplus. If the bargaining breaks down, both producers get zero. Hence the surplus equals the total value of the match. We use the Nash bargaining solution, so any pair of producers that forms a match will divide the total match value equally between them. After a match is concluded the partnership demands the profit-maximizing quantity of labor, taking the wage rate as given. When all labor demands are received, the labor market clears. 
With a constant returns to scale production function, total profits from the match of types $i$ and $j$ can be written as:

$$
\prod_{i j}=z_{i j} \pi(w)
$$

where $w$ is the wage paid to labor employed by the partnership, and the function $\pi(w)$ is decreasing and convex in $w$. For ease of later proofs, let us also assume that $\pi(w)$ is a constant elasticity function (as would be the case, for example, if the technology were Cobb-Douglas). The labor demand generated by a partnership is then given by:

$$
L_{i j}^{d}=-z_{i j} \pi^{\prime}(w)
$$

where the prime sign indicates the first derivative.

We assume that every domestic producer knows at least the location of his best domestic match type. In this case it seems natural to focus on the efficient equilibrium in which each domestic producer selects the producer opposite him on the circle (and at the same height on the cylinder). This is an equilibrium since no producer has an incentive to change his behavior after he has chosen and been chosen by his perfect complement.

In this autarky equilibrium $z_{i j}=1 / 2$ for every partnership. Since every producer succeeds in forming a partnership and receives half of the profits, each producer earns $(1 / 2)(1 / 2) \pi(w)=$ $\pi(w) / 4$. This is also the value of total profits because the mass of producers equals one. Total labor demand is then $-\pi^{\prime}(w) / 4 .^{7}$ The autarky equilibrium wage is determined by $-\pi^{\prime}(w) / 4=L$ in the home country and $-\pi^{\prime}\left(w^{*}\right) / 4=L^{*}$ in the foreign country, respectively. It is easily seen that wages are lower and profits are higher in the labor-abundant (foreign) country, as expected.

\footnotetext{
${ }^{7}$ Alternatively, we can note that each partnership generates a labor demand equal to $-\pi^{\prime}(w) / 2$, and that the mass of partnerships equals $1 / 2$.
} 


\section{International trade 8}

In our model international trade takes place as follows. Home country producers travel costlessly to the foreign country, where foreign producers await them. Each home country producer draws a potential foreign partner from a distribution over the circle of types that is uniform with support of length $k \in(0,1]$ and has its median at the producer's opposite type (see Figure 1). ${ }^{9} k$ thus serves as an index of familiarity, with a lower $k$ corresponding to greater familiarity. Types are revealed in international partnerships, but they differ from domestic partnerships in two ways..$^{10}$ First, international partnerships can employ labor in whichever country it is cheaper, rather than having access only to domestic labor. Second, the profits of home country producers from international partnerships are taxed by the home country government at rate $t \in[0,1)$. Since the existence of tax revenue is irrelevant for our results (because we do not analyze welfare), $t$ could be seen equivalently as the proportion of the numeraire good in which home country producers repatriate their profits that "melts" in transport.

If their international match is unsuccessful, both the home and foreign producers seek domestic partnerships with other home and foreign producers, respectively, whose international matches were also unsuccessful. ${ }^{11}$ Domestic partnerships are formed as in the autarky

${ }^{8}$ This subsection again builds on Rauch and Casella (1998).

${ }^{9}$ This is consistent in the aggregate due to the symmetry of the circle and uniform distribution of home and foreign producers over types.

${ }^{10} \mathrm{We}$ shall see shortly that the threat point is the same for all types within a country, so it is not clear that anything could be gained by misrepresenting one's type if this were possible.

${ }^{11}$ Our model could potentially be extended to a dynamic framework in which, on the one hand, home producers learn about their foreign counterparts through costly resampling and, on the other hand, their knowledge decays due (for example) to entry and exit of foreign producers. We 
equilibrium described in the previous subsection. It follows that if both domestic markets are active the threat points in international bargaining of every home and every foreign producer are $\pi(w) / 4$ and $\pi\left(w^{*}\right) / 4$, respectively, where $w$ and $w^{*}$ are the international trade equilibrium wages. ${ }^{12}$ International matches are successful if and only if this domestic alternative is inside the Pareto frontier (see Figure 2). The home and foreign labor markets clear when all demands for labor, from domestic and international partnerships, are received.

We will show in the next section that the foreign wage is always strictly less than the home wage in international trade equilibrium. The attraction of international partnerships for home producers is therefore access to cheap labor. The attraction for foreign producers is the weaker bargaining power of international than domestic partners. Since all international partnerships employ foreign labor, trade serves to transfer labor demand from the country where labor is scarce to the country where it is abundant, as in standard trade models.

\section{International trade equilibrium and comparative statics}

Both home and foreign labor markets must clear in international trade equilibrium. To find these market-clearing conditions we must derive the demands for home and foreign labor. The key step in this derivation is to find which international partnerships are successful, which in turn determines how much labor demand is transferred from the home to the foreign country.

choose to keep our model static for simplicity, which is especially important when we derive results on changes in elasticities in sections V and VI, and to keep as close to standard trade models as possible.

${ }^{12}$ Atomless producers and the symmetry of the position of every producer on the circle ensure that the height of the remaining cylinder of producers in each country is the same for every type and thus domestically every producer can still match with his opposite type. 
If a home country producer of type $i$ draws a potential foreign partner of type $j$, denote their distance on the circle of types by $z_{i j}$, as represented in Figure $1 . z_{i j}$ is uniformly distributed on the interval $[1 / 2-k / 2,1 / 2]$, where $k \in(0,1]$. Given the symmetry of the circle we can drop the subscripts from $z_{i j}$ : every home country producer faces a uniform distribution of partner distance $z$, with support $[1 / 2-k / 2,1 / 2]$ on the circle. We represent in Figure 2 the possibilities set that results from a potential international partnership. Note that the frontier is not a $45^{\circ}$ line, since only the home producer is taxed. If the threat point is inside the Pareto frontier (the case shown in Figure 2) the two parties have an incentive to produce together, since they have a positive surplus to divide. For symmetry with domestic partnerships we apply the Nash bargaining solution to the outcome of this process, though none of our results depend on this assumption.

The condition that the threat point is inside the Pareto frontier can be expressed as:

$$
\begin{aligned}
& \pi\left(w^{*}\right) / 4<-\pi(w) /[4(1-t)]+z \pi\left(w^{*}\right), \text { or alternatively as } \\
& z>1 / 4+\psi /[4(1-t)]
\end{aligned}
$$

where $\psi\left(w^{*} / w\right) \equiv \pi(w) / \pi\left(w^{*}\right)$ and $\psi^{\prime}>0$. This cutoff condition is represented in Figure 1 . Note that we can write $\psi$ as a function of only the ratio of wages because $\pi$ is a constant elasticity function. In what follows we will loosely speak of the function $\psi$ as the "wage ratio," which should not cause any confusion because it is just a scaling of the wage ratio.

From equation (4) we can see that no international partnerships can be successful if $w=$ $w^{*}$ (i.e., $\psi^{\prime}=1$ ): simply recall that $z$ cannot exceed $1 / 2$. It follows that $w=w^{*}$ cannot be an equilibrium since the autarky wage must be lower in the foreign (labor abundant) country. We can also rule out $w<w^{*}$ because then all demand for labor from international partnerships falls 
on home labor, yielding $w>w^{*}$, a contradiction. We therefore know that $w>w^{*}$ in any international trade equilibrium, so that all demand for labor from international partnerships falls on foreign labor.

Equation (4) actually yields a tighter restriction on the relationship of wages in international trade equilibrium. We see that no international partnerships can be successful if $\psi \geq 1$ - $t$. If $\psi$ evaluated at autarky wages is greater than or equal to $1-t$, we can say that the tax rate is prohibitive. We will only consider non-prohibitive tax rates for the remainder of this paper. It follows that 1-t is an upper bound for $\psi$, yielding an upper bound for $w^{*} / w$ that is less than one. We also see from equation (4) that if $\psi<(1-2 k)(1-t) \equiv \alpha$, all international partnerships are successful. But then demand for home labor falls to zero and $\psi>1$, a contradiction. It must then be that

$$
\psi \in(\max (0, \alpha), 1-t) .
$$

Given these preliminaries, we are now ready to compute labor demands. Before doing so, however, it builds intuition to compute the probability that any international partnership will be successful. From Figure 1 we see that this is given by

$$
\begin{aligned}
& P=\frac{\frac{1}{2}-\left(\frac{1}{4}+\frac{\psi}{4(1-t)}\right)}{k / 2}, \text { or, simplifying, } \\
& P=\frac{1-t-\psi}{2 k(1-t)}
\end{aligned}
$$

As expected, the probability of success is higher when the wage ratio is smaller, when the tax rate decreases (holding $\psi$ constant), and when familiarity increases (again holding $\psi$ constant). Also note that the sensitivity of $P$ to both the wage ratio and the tax rate is greater when 
familiarity is greater ( $k$ is smaller). This indicates the ability of producers to respond more effectively to price-based incentives, as discussed at the end of section II. Specifically, equation (6) reflects the fact that the density of producers that are "on the margin" between matching internationally and matching domestically increases as $k$ decreases. The underlying cause for the positive relationships between familiarity and both labor market integration and the impact of trade liberalization is thus contained in equation (6). ${ }^{13}$

Home labor is demanded only by those home producers whose international matches were unsuccessful. Summing, we get:

$$
\begin{aligned}
& \frac{2}{k} \int_{1 / 2-k / 2}^{\frac{1-t+\psi}{4(1-t)}} \frac{1}{4}\left(-\pi^{\prime}(w)\right) d z=\left(\frac{1}{4}-\frac{1-t-\psi}{8 k(1-t)}\right)\left(-\pi^{\prime}(w)\right) \\
& =(1-P) \frac{1}{4}\left(-\pi^{\prime}(w)\right),
\end{aligned}
$$

where we used the fact that the mass of home producers equals one and applied the definition of $P$ in the last line. Note that we used the symmetry of the problem to integrate over only half the interval in Figure 1, dividing by $k / 2$ instead of $k$. As expected, home labor demand is increasing in $\psi:$ as $\psi$ increases, the share of international matches that is successful falls.

Foreign labor demand is the sum of labor demand by foreign producers whose international matches were unsuccessful and labor demand from successful international partnerships:

\footnotetext{
${ }^{13}$ The parallel between the two results is not perfect, however, because the effects on the probability that an international partnership will be successful of the wage ratio $\psi$ and the trade tax $t$ are not perfectly symmetric in equation (6), and because the wage ratio is endogenous whereas the tax rate is not. See Propositions 5 and 7 in sections V and VI, respectively.
} 


$$
\begin{aligned}
& \frac{2}{k}\left(\int_{1 / 2-k / 2}^{\frac{1-t+\psi}{4(1-t)}} \frac{1}{4}\left(-\pi^{\prime}\left(w^{*}\right)\right) d z+\int_{\frac{1-t+\psi}{4(1-t)}}^{1 / 2} z\left(-\pi^{\prime}\left(w^{*}\right)\right) d z\right)= \\
& \left(\frac{1}{4}+\frac{\left.(1-t)^{2}-\psi^{2}\right)}{16 k(1-t)^{2}}\right)\left(-\pi^{\prime}\left(w^{*}\right)\right)= \\
& (1-P) \frac{1}{4}\left(-\pi^{\prime}\left(w^{*}\right)\right)-\frac{\partial Q}{\partial w^{*}} .
\end{aligned}
$$

Note that foreign labor demand is decreasing in $\psi$ as expected. In the last line of equation $\left(7^{*}\right)$ we introduce a new quantity, $Q$, which equals the profits from all successful international partnerships. In other words, $Q$ is the same as the second integral in equation $\left(7^{*}\right)$ if we replace $\left(-\pi^{\prime}\left(w^{*}\right)\right)$ by $\pi\left(w^{*}\right)$. Since $\pi\left(w^{*}\right)$ factors out of the integral, we can recover the labor demand integral if we take the derivative of the negative of $Q$ with respect to $w^{*}$.

Given equations (7) and $\left(7^{*}\right)$, we can write the labor market clearing conditions as:

$$
\begin{aligned}
& \left(\frac{1}{4}-\frac{1-t-\psi}{8 k(1-t)}\right)\left(-\pi^{\prime}(w)\right)=L, \\
& \left(\frac{1}{4}+\frac{\left.(1-t)^{2}-\psi^{2}\right)}{16 k(1-t)^{2}}\right)\left(-\pi^{\prime}\left(w^{*}\right)\right)=L^{*}
\end{aligned}
$$

Since $w^{*}$ can be expressed as $\pi^{-1}(\pi(w) / \psi)$, equations (8) and $\left(8^{*}\right)$ constitute two equations in two unknowns, $w$ and $\psi$. We can now prove:

Proposition 1: An international trade equilibrium exists and is unique. Proof: An equilibrium exists if there is a $\psi \in(\max (0, \alpha), 1-t)$ and a $w>0$ that are solutions to the system formed by (8) and $\left(8^{*}\right)$. Combining these two equations yields:

$$
\frac{2(1-t)(\psi-\alpha)}{(1+4 k)(1-t)^{2}-\psi^{2}} g(\psi)=R \text {. }
$$

where we use the definitions $R \equiv L / L^{*}$ and $g(\psi) \equiv \pi^{\prime}(w) / \pi^{\prime}\left(w^{*}\right)$. Note that we can write $g$ as a 
function of $\psi$ because $\pi^{\prime}$ is a constant elasticity function. Furthermore, $g$ is an increasing function of $\psi$, with $g(0)=0$ and $g(1)=1$. It is clear that the left-hand side of equation (9) is a monotonically increasing function of $\psi$, so if a solution for $\psi$ exists it is unique. If $L / L^{*}=0$ then the unique solution is either $\psi=\alpha$ or $\psi=0$, depending on which of these values is larger. This is just the lower bound for $\psi$ in equation (5). Now suppose that $\psi=1-t$, its upper bound. Equation (9) then becomes $g(1-t)=R$. But it can be shown that $R<\mathrm{g}(1-t)$ is the condition for the tax rate to be non-prohibitive. This proves that a solution for $\psi$ exists and is unique. This solution can be substituted into equation (8). It is trivial to prove that

$$
\frac{1}{4}-\frac{1-t-\psi}{8 k(1-t)}>0
$$

in that equation, given our bounds for $\psi$. Then, because $\pi^{\prime}$ is a monotonic constant elasticity function, a unique $w$ exists that solves equation (8).

We can now perform comparative statics analysis. In Figure 3 we plot equations (8) and $\left(8^{*}\right)$ in $\{w, \psi\}$ space as the curves $L L$ and $L^{*} L^{*}$, respectively. It is easy to prove that $L L$ must slope upwards and $L^{*} L^{*}$ downwards, but we give only the intuition here. Home labor demand is increasing in $\psi$, so $w$ must increase to maintain labor market clearing, yielding an upward slope to $L L$. Foreign labor demand is decreasing in $\psi$, so $w^{*}$ must decrease to maintain labor market clearing, which in turn requires a decrease in $w$ since $w^{*}=\pi^{-1}(\pi(w) / \psi)$, yielding a downward slope to $L^{*} L^{*}$.

Now consider an increase in $L$. At constant $w, \psi$ must increase to maintain labor-market clearing, hence the $L L$ curve shifts up. The home wage falls absolutely and relative to the foreign wage (which also falls absolutely by equation $\left(8^{*}\right)$ ). An increase in $L^{*}$ causes the $L^{*} L^{*}$ curve to shift down, reducing the equilibrium $\psi$. The foreign wage falls absolutely and relative to the home wage (which also falls absolutely by equation (8)). We thus see that with less than complete familiarity $(k>0)$ national labor markets are partially integrated in the sense that, although an increase in either country's labor supply causes both its wage and that of its trading partner to fall, its wage falls more. In the next section we will show that the extent of labor 
market integration increases monotonically with familiarity.

Turning to an increase in $k$, we see that the left-hand sides of equations $(8)$ and $\left(8^{*}\right)$ are increasing and decreasing in $k$, respectively. Labor market clearing then requires a lower $\psi$ for any $w$ in both equations, shifting both the $L L$ and $L^{*} L^{*}$ curves down. As familiarity decreases, less labor demand is transferred from the home to the foreign country and the foreign wage falls relative to the home wage. As expected, the same result can be demonstrated for an increase in $t$. To see that the left-hand side of equation (8) is increasing in $t$, we simply rewrite it as

$$
\left(\frac{1}{4}-\frac{1}{8 k}\left(1-\frac{\psi}{1-t}\right)\right)\left[-\pi^{\prime}(w)\right]=L .
$$

We can in an analogous way see that the left-hand side of equation $\left(8^{*}\right)$ is decreasing in $t$. Again, the last two observations taken together imply that $\psi$ will decrease with increasing $t$.

Intuitively, we also expect that $w$ increases and $w^{*}$ decreases with increasing $k$ or $t$, but these results cannot be demonstrated using Figure 3. Instead, they are proved in the next Proposition:

Proposition 2: With changes in $\mathrm{k}$ or $\mathrm{t}$ the following results apply:

i) $\quad d w / d k>0$.

ii) $\quad d w / d t>0$.

iii) $\quad d w^{*} / d k<0$.

iv) $\quad d w^{*} / d t<0$.

Proof: Because as noted above $d \psi / d k<0$ and $d \psi / d t<0$, then it suffices to prove that $(d w / d k)\left(d w^{*} / d k\right)<0$ and that $(d w / d t)\left(d w^{*} / d t\right)<0$. The most straightforward way to do this is simply to substitute the definition $\psi\left(w^{*} / w\right) \equiv \pi(w) / \pi\left(w^{*}\right)$ in equations (8) and $\left(8^{*}\right)$, and then to totally differentiate the resulting two equations. The results can be summarized as follows:

$$
\left(\begin{array}{cc}
A & B \\
C & D
\end{array}\right)\left(\begin{array}{c}
d w \\
d w^{*}
\end{array}\right)=\left(\begin{array}{cc}
F & G \\
H & I
\end{array}\right)\left(\begin{array}{l}
d k \\
d t
\end{array}\right),
$$

where the matrix coefficients are functions of $w, w^{*}$, and the parameters of the model. Then a straightforward use of Cramer's rule reduces the proof to showing that: 
$(D F-B H)(A H-C F)<0$ and

$(D G-B I)(A I-C G)<0$.

The proofs of these inequalities, as well as the explicit expressions for the coefficients, are relegated to an appendix available upon request.

We next show that, as either type of trade barrier increases (either familiarity decreases or the tax rate increases), the volume of trade decreases, as expected. In our model the volume of trade equals profits repatriated by home country producers. The following Lemma will be an important input to our proof:

Lemma: The probability of a successful match $\mathrm{P}$ decreases as either $\mathrm{k}$ or $\mathrm{t}$ increases. Proof: The results follow from Proposition 2 and the last line of equation (7). Since $w$ increases with $k$ or $t$, it must be that $P$ decreases, in either case, to keep labor demand constant.

Proposition 3: The volume of trade decreases as either $\mathrm{k}$ or $\mathrm{t}$ increases. Proof: Since from Proposition 2 we have $d w / d k>0$ and $d w / d t>0$, it suffices to show that the total profits from international partnerships $Q$ decrease as either $k$ or $t$ increases, because the weakening of the bargaining position of home country producers means the profits they obtain from international partnerships decrease even more. Consider an increase in $k$. We know from Proposition 2 and the Lemma that both $w^{*}$ and $P$ go down, both thereby contributing to an increase in the demand for foreign labor according to the last line of equation $\left(7^{*}\right)$. Since the foreign labor market must still clear, it must be that $-\partial Q / \partial w^{*}$ (which is a positive quantity) decreases. Since the expression for $Q$ is proportional to $\pi\left(w^{*}\right)$, it can be written as $Q=C\left(w^{*}\right)^{-\varepsilon}$, where $C$ does not depend on $w^{*}$ and $-\varepsilon$ is the constant elasticity of profits with respect to the wage rate. Then $-\partial Q / \partial w^{*}=$ $C \varepsilon\left(w^{*}\right)^{-\varepsilon-1}=\varepsilon Q / w^{*}$, and since $w^{*}$ is decreasing it must be that $Q$ itself decreases with $k$. The proof for the case when $t$ increases is exactly analogous.

We conclude this section by proving our first "convergence" result: in the limit as familiarity becomes complete ( $k$ approaches zero), the ratio of national wages becomes a function of only the trade tax and technology, as in the $2 \times 2$ Heckscher-Ohlin-Samuelson model and the standard one-good, two-factor model of trade in factor services. In particular, the ratio of national wages becomes independent of the ratio of national labor supplies.

Proposition 4: As k approaches zero, $\psi$ approaches 1-t. Proof: Move the denominator of equation (9) to the right-hand side, substitute for the definition of $\alpha$, and rearrange to get: 


$$
4 k(1-t)^{2}[g(\psi)-R]=(1-t-\psi)[R(1-t+\psi)+2(1-t) g(\psi)] .
$$

When $k \rightarrow 0$ the left-hand side goes unambiguously to zero. Since the term in brackets on the right-hand side is always positive, we must have $\psi \rightarrow 1-t$.

Alternatively, we could note that as $k$ approaches zero, $\alpha$ approaches $1-t$, and the lower and upper bounds for $\psi$ converge on 1-t by equation (5).

The equation $\psi=1-t$ implies that the wage ratio depends only on the trade tax and on production technology, which determines the mapping from $\psi$ to $w * / w . \psi$ achieves its upper bound because with perfect familiarity the maximum transfer of labor demand from the home to the foreign country occurs.

\section{Familiarity and labor market integration}

As stated in the Introduction, we want to show that national wage rates tend to move together more in response to changes in national labor supplies as informational barriers to trade fall. This aspect of international labor market integration can be measured by the elasticity of the wage ratio with respect to the ratio of national labor endowments. If country wage rates change equiproportionately in response to changes in either country's labor supply, this elasticity is zero; the less integrated are national labor markets, the greater is this elasticity.

For convenience the elasticity we will actually work with is:

$$
e_{\psi, R}=\frac{R}{\psi} \frac{\partial \psi}{\partial R}
$$

recalling the definitions $\psi\left(w^{*} / w\right) \equiv \pi(w) / \pi\left(w^{*}\right)$ and $R \equiv L / L^{*}$. Using the fact that $\pi(w)$ is a constant elasticity function, it is easily shown that $\psi$ reduces to $\left(w^{*} / w\right)^{\varepsilon}$ (where $-\varepsilon$ is the constant elasticity), so that $e_{\psi, R}=\varepsilon e_{w^{*} / w, R}$. Changes in the $e_{\psi, R}$ are thus equivalent to changes in the 
elasticity of the ratio of national wages with respect to the ratio of national labor supplies. Note that we know from the comparative static results in section IV that $e_{\psi, R}$ is positive.

In section II we argued that, as familiarity increases, firms are able to transfer labor demand more effectively between countries in response to the opportunities presented by wage differentials, thereby reducing the extent to which relative wages need to change when relative labor supplies change in order for national labor markets to clear. We will now demonstrate this result formally.

Proposition 5: $e_{\psi, R}$ increases with $\mathrm{k}$. Proof: The equilibrium $\psi$ is calculated with the help of Equation (9), which we repeat here:

$$
\frac{2(1-t)(\psi-\alpha)}{(1+4 k)(1-t)^{2}-\psi^{2}} g(\psi)=R \text {. }
$$

This equation implicitly defines $\psi$ as a function of $R$. Taking derivatives and substituting the equation back in, we get

$$
\frac{\psi}{R} \frac{\partial R}{\partial \psi}=\left(\frac{g^{\prime}(\psi) \psi}{g(\psi)}+\frac{\psi}{\psi-\alpha}+\frac{2 \psi^{2}}{(1+4 k)(1-t)^{2}-\psi^{2}}\right),
$$

which is just the inverse of $e_{\psi, R}$. We wish to prove that this decreases with $k$. Consider each term inside the parenthesis. The first term is just the elasticity of the function $g$, which does not change with $k$. The third term clearly decreases with $k$. We then complete the proof by showing that the second term decreases with $k$. We know that $\psi$ decreases with $k$. We can find out how $\psi-\alpha$ changes with $k$ by using the definition of $P$ (equation (6)). We have:

$$
1-P=\frac{\psi-\alpha}{2 k(1-t)} \text {. }
$$

Since 1-P increases when $k$ increases (by the Lemma), it must be that $\psi-\alpha$ increases as well. It follows that the second term above decreases with $k$.

Proposition 5 shows that the elasticity of relative national wages with respect to relative national labor supplies is decreasing in familiarity. We can go further and show that in the limit as familiarity becomes complete ( $k$ approaches zero) this elasticity goes to zero, its value in the 2 $\times 2$ Heckscher-Ohlin-Samuelson model and in the standard one-good, two-factor model of trade 
in factor services. This is our second convergence result. Consider our expression for the inverse of $e_{\psi, R}$ in the proof of Proposition 5, and focus on the term that contains $\psi-\alpha$ in the denominator. From the definition of $\alpha$, we see that $\alpha$ goes to $1-t$ as $k$ goes to zero. We also know from Proposition 4 that $\psi$ goes to 1-t as $k$ goes to zero. It follows that $\psi-\alpha$ goes to zero as $k$ goes to zero. We then see that the inverse of $e_{\psi, R}$ becomes infinite, so that the elasticity of relative national wages with respect to relative national labor supplies approaches zero as informational barriers to trade vanish.

Figure 4 shows Proposition 5 in action. The percentage changes in the home wage, foreign wage, and ratio of the former to the latter in response to a 10 percent increase in the foreign labor supply are plotted against $1 / k$, where $k$ falls from 1 to 0.05 . The value of $t$ in this simulation is zero. The initial value of $R$ in this simulation is $1 / 2$, so the world labor supply increases by $62 / 3$ percent. The value of $\varepsilon$ is 1 , yielding an autarky labor demand elasticity of 2 , so in a perfectly integrated world labor market the world wage should fall by $31 / 3$ percent (actually about 3.175 percent once we correct for linear approximation error). We see from Figure 4 that for minimum familiarity the home wage falls by less than 1 percent and the foreign wage falls by more than 4 percent in response to the 10 percent increase in foreign labor supply, but as familiarity increases these changes both converge towards the perfectly integrated world labor market value and the change in the wage ratio converges towards zero.

In a recent book, Rodrik (1997) argues that globalization increases the insecurity felt by workers in high-wage countries. An important part of his argument is that globalization increases the elasticity of national labor demand. We can easily show that an increase in familiarity has this effect in our model. We have just shown that the impact of a change in 
domestic labor supply tends to be felt less on domestic wages relative to wages abroad as familiarity increases. If a given change in domestic labor supply is associated with a smaller change in domestic wages, a given change in domestic wages will be associated with a larger change in domestic labor demand. Following Rodrik, we consider the elasticity of domestic labor demand in the high-wage country ignoring any effect of the change in domestic wages on wages in the rest of the world. We can think of this elasticity as a partial equilibrium magnitude, as would be typical in labor economics, or we can think of it as a general equilibrium magnitude, in which case the home country must be "small" relative to the foreign country. ${ }^{14}$

We define the elasticity of home country labor demand as

$$
\widetilde{e}_{L^{d}, w}=\frac{w}{L^{d}} \frac{\partial L^{d}}{\partial w} \quad\left(w^{*} \text { constant }\right)
$$

where $L^{d}$ is the demand for home labor (the left-hand side of equation (8)) and the tilde reminds us that this elasticity is calculated at constant $w^{*}$. We can now prove:

Proposition 6: $\widetilde{e}_{L^{d}, w}$ decreases with $\mathrm{k}$ in absolute value. Proof: Use of equation (8) gives us:

$$
L^{d}=\frac{\psi-\alpha}{8 k(1-t)}\left[-\pi^{\prime}(w)\right]
$$

Then, by taking derivatives:

\footnotetext{
${ }^{14} \mathrm{We}$ can implement the small country assumption rigorously in our model by allowing the foreign producer cylinder to become infinitely tall, while at the same time allowing the foreign labor endowment to grow proportionately so that the foreign autarky wage is unchanged. In this way the measure of foreign producers that match with home producers goes to zero, permitting us to treat the foreign wage $w^{*}$ as a constant when the home wage varies. The home labormarket clearing condition does not change because with one-shot random matching the probability of formation of successful partnerships by home producers does not change.
} 


$$
\begin{aligned}
& \frac{w}{L^{d}} \frac{\partial L^{d}}{\partial w}=\frac{w}{L^{d}} \frac{-\left(\pi^{\prime}(w)\right)^{2} / \pi\left(w^{*}\right)-(\psi-\alpha) \pi^{\prime \prime}(w)}{8 k(1-t)}= \\
& \frac{-w\left(\pi^{\prime}(w)\right)^{2} / \pi\left(w^{*}\right)-w(\psi-\alpha) \pi^{\prime \prime}(w)}{(\psi-\alpha)\left(-\pi^{\prime}(w)\right)}=-\frac{\varepsilon \psi+(\varepsilon+1)(\psi-\alpha)}{\psi-\alpha},
\end{aligned}
$$

where we recall that $-\varepsilon=w \pi^{\prime}(w) / \pi(w)$ is the elasticity of $\pi(w)$. We note that the last expression is unambiguously negative. We want to prove that it increases (decreases in absolute value) when $k$ increases. Rewrite it as:

$$
\widetilde{e}_{L^{d}, w}=-\frac{\varepsilon \psi}{\psi-\alpha}-\varepsilon-1
$$

We showed in the proof of Proposition 5 that, comparing across equilibria, $\psi /(\psi-\alpha)$ decreases with $k$. This completes the proof of the present Proposition if we interpret $\widetilde{e}_{L^{d}, w}$ as a partial equilibrium magnitude. In the case where $\widetilde{e}_{I^{d} w}$ is a general equilibrium magnitude (the home country is small relative to the foreign country), however, we need to show that $\psi /(\psi-\alpha)$ decreases with $k$ comparing across equilibria in which the home country is small relative to the foreign country. We first show by contradiction that $\psi$ decreases with $k$. Suppose that $\psi$ does not decrease. At constant $w^{*}$ this immediately implies that $w$ does not increase. It is then immediately clear from equation (8) that the home labor market cannot clear. We next show by contradiction that $\psi$ - $\alpha$ increases with $k$. Suppose that $\psi$ - $\alpha$ does not increase. Since $\psi$ decreases and $w^{*}$ is constant, $w$ increases. We then see that all the terms in the expression for home labor demand given at the beginning of this proof decrease, so the home labor market cannot clear. Since $\psi /(\psi-\alpha)$ decreases with $k, \widetilde{e}_{L^{d}, w}$ decreases with $k$ (in absolute value).

In the discussion following the proof of Proposition 5 above we noted that $\psi-\alpha$ goes to zero as $k$ goes to zero. ${ }^{15}$ We see from equation (10) that this implies that the elasticity of home labor demand holding the foreign wage constant becomes infinite as familiarity becomes complete. The results of our model again converge to the results of standard trade models as $k$ goes to zero.

Figure 5 illustrates Proposition 6. The home labor demand curve is plotted for four

\footnotetext{
${ }^{15}$ This result can easily be shown to also hold in the case where the home country is small relative to the foreign country.
} 
values of $k$. The home wage and the home labor demand are expressed in proportion to the foreign wage and foreign labor supply, respectively. ${ }^{16}$ The value of $\varepsilon$ is 1 , as in Figure 4, but the value of $t$ is 0.1 , its (initial) value in Figures 6 and 7 below. It follows that when $w / w^{*}$ falls to $1 / 0.9(\psi$ rises to $0.9=1-t)$ the home country is in autarky, so that labor demand is the same regardless of the value of $k .{ }^{17}$ Figure 5 shows that the home labor demand curve tends towards a horizontal line as $k$ approaches zero, though it is perhaps surprising that this tendency does not clearly manifest itself until familiarity becomes close to complete.

\section{Familiarity and the impact of trade liberalization}

One of the most important aspects of informational barriers to international trade is their interaction with conventional trade barriers. We argued in section II that, just as informational barriers interfere with the ability of firms to transfer labor demand across borders in response to the incentive of international wage differentials, they would also blunt their shifting of labor demand in response to the disincentive of trade taxes. The reduced ability to respond to wage differentials as $k$ increases leads to an increase in the elasticity of the ratio of national wages with respect to the ratio of national labor supplies, as we demonstrated in Proposition 5. The corresponding result for trade taxes should then be a decrease in the elasticity of the wage ratio (in absolute value) as $k$ increases.

\footnotetext{
${ }^{16}$ In the case where the home country is small relative to the foreign country, we must instead state that the home labor demand per producer is expressed in proportion to the foreign labor supply per producer.
}

${ }^{17}$ The reader can easily compute that, for $\varepsilon=1$, the value of $R$ for which $t=0.1$ is a "prohibitive" tax rate is $(0.9)^{c+1}=0.81$. 
We saw following Proposition 5 that $e_{y, R}$ tends to 0 as $k$ tends to 0 . Towards what quantity should we expect the elasticity of the wage ratio with respect to trade taxes to tend as $k$ tends to 0 ? Proposition 4 tells us that $\psi$ tends to $1-t$ as $k$ tends to 0 , and it is easily shown that the equation $\psi=1-t$ yields an elasticity of $\psi$ with respect to $t$ equal to $-t /(1-t)$. The dependence on $t$ is awkward, so we make the change of variable $T \equiv 1-t$, in which case the equation $\psi=1-t \equiv T$ yields an elasticity of $\psi$ with respect to $T$ equal to 1 . An increase in $T$ corresponds to trade liberalization or to an increase in the proportion of the traded good that "arrives" in the ice transport cost model. Defining

$$
e_{\psi, T}=\frac{T}{\psi} \frac{\partial \psi}{\partial T}
$$

we expect $e_{\psi, T}$ to approach 1 as $k$ approaches 0 . The elasticity of $w^{*} / w$ with respect to trade liberalization is then given by $e_{w^{*} / w, T}=e_{\psi, T} / \varepsilon$. Note that we know from the comparative static results in section IV that $e_{y /, T}$ is positive.

We demonstrate in Proposition 7 that the extent to which trade liberalization equalizes wages across countries increases with familiarity, and $e_{\psi, T}$ approaches 1 as familiarity becomes complete:

Proposition 7: $e_{y, T}$ decreases with $\mathrm{k}$, and $e_{y, T} \rightarrow 1$ as $\mathrm{k} \rightarrow 0$. Proof: The proof of this proposition is more involved than the proofs of our other propositions, and is confined to the Appendix.

Figure 6 shows Proposition 7 in action. The percentage changes in the home wage, foreign wage, and ratio of the latter to the former in response to a 10 percent increase in $T$ are plotted against $1 / k$, where $k$ falls from 1 to 0.05 . The value of $R$ in this simulation is $1 / 2$ and the 
initial value of $T$ is $0.9(t=0.1)$. The value of $\varepsilon$ is 1 , so the increase in $w^{*} / w$ must approach 10 percent as $k$ approaches 0 . We see from Figure 6 that for minimum familiarity the foreign wage relative to the home wage increases by about $21 / 2$ percent, while for $k=0.05$ this ratio increases by nearly 9 percent, close to the value of 10 percent that would obtain with complete familiarity. This equalization of wages in response to trade liberalization is brought about more by a fall in the home wage than by an increase in the foreign wage, reflecting the larger size of the foreign labor force.

We conclude this section with a result on "pass-through" of changes in trade taxes to domestic wages. Since conventional pass-through analysis treats foreign prices as given we will hold $w^{*}$ constant in our analysis. As for Proposition 6 on the elasticity of domestic labor demand, we can either justify this assumption by making the home country "small" relative to the foreign country or consider our analysis to be of the partial rather than general equilibrium variety. Our result holds in either case.

We define

$$
\widetilde{e}_{w, T}=\frac{T}{w} \frac{\partial w}{\partial T} \quad\left(w^{*} \text { constant }\right)
$$

as our measure of the rate of pass-through. Since from Proposition 7 we already know that $w^{*} / w$ changes less in response to a change in $T$ as $k$ increases, we can expect that if we hold $w^{*}$ constant $w$ will change less in response to a change in $T$ as $k$ increases. We verify that the rate of pass-through increases as familiarity increases in Proposition 8:

Proposition 8: The absolute value of $\widetilde{e}_{w, T}$ decreases with $\mathrm{k}$. Proof: By making the change of variable $T \equiv 1-t$ in equation (8) and differentiating, we can calculate: 


$$
\widetilde{e}_{w, T}=\frac{\pi^{\prime}(w)}{w \pi^{\prime \prime}(w)} \frac{\psi}{(1+\varepsilon /(1+\varepsilon)) \psi-\alpha} .
$$

Note that the first fraction on the right does not depend on $k$. Inverting the last fraction, we then want to prove that its inverse increases with $k$, which amounts to proving that $\alpha / \psi$ decreases with $k$. In Propositions 5 and 6 , respectively, we proved that $\psi-\alpha$ increases and $\psi$ decreases as $k$ increases, for the case where $w^{*}$ is held constant in partial equilibrium and for the case where the home country is small relative to the foreign country. This implies that $(\psi-\alpha) / \psi=1-(\alpha / \psi)$ increases with $k$, which in turn implies the desired result.

In standard trade models, pass-through of changes in trade taxes to domestic wages is "complete" in the sense that it equals the percentage change in $T$ multiplied by a coefficient that is determined only by the underlying production technology. ${ }^{18}$ It is easily shown that this property obtains in our model as familiarity becomes complete. Consider the expression for $\widetilde{e}_{w, T}$ in the preceding proof. The first fraction equals $-1 /(1+\varepsilon)$, and $\psi$ approaches $\alpha$ as $k$ approaches zero, so $\widetilde{e}_{w, T} \rightarrow-1 / \varepsilon$ when $k \rightarrow 0$ and the percentage change in the home wage approaches the percentage change in $T$ multiplied by $-1 / \varepsilon$. The coefficient $-1 / \varepsilon$ is of course the value of $\widetilde{e}_{w, T}$ implied by the equation $\psi=T$. This is our final "convergence" result.

We know from Proposition 3 that the volume of trade increases with familiarity. Proposition 8 therefore implies that the impact of trade liberalization on domestic wages will be greater, the greater is the initial volume of trade, holding constant all parameters other than familiarity, including the initial level of the trade tax and all characteristics of the trading partner.

Figure 7 illustrates Proposition 8 . The vertical axis measures the percentage change in the home wage in response to a 10 percent increase in $T$. The (initial) value of $T$ is 0.9 and the

\footnotetext{
${ }^{18}$ In the $2 \times 2$ Heckscher-Ohlin-Samuelson model we would define $T$ as $1+t$ rather than $1-t$, where $t$ is an ad valorem tariff rather than a profits tax.
} 
value of $\varepsilon$ is 1 , as in Figure 6, so that complete pass-through would yield a percentage change in the home wage of $-10=(-1 / \varepsilon)(10)$. We see that for minimum familiarity the home wage decreases by about 2 percent, compared to a decrease of about 7 percent for $k=0.05$. In this simulation a substantial amount of protection remains for home labor relative to full pass-through even when familiarity is nearly complete.

\section{Conclusions}

We modeled a reduction in informational barriers to trade as an increase in familiarity with the set of potential partners in a labor-abundant country with which investors from a laborscarce country can enter into productive joint ventures. We found that increased familiarity leads to greater integration of national labor markets in the sense that an increase in one country's labor supply has more nearly equal proportionate effects on its wages and those in its trading partner. A related result is that, unlike reductions in conventional trade barriers (at least in standard models), greater familiarity has the effect predicted by Rodrik (1997) of increasing the elasticity of national labor demands. A further important implication of our model is that, even if conventional trade barriers were to be eliminated, the process of trade-driven convergence of national wage levels need not have run its course.

In our model conventional trade barriers took the form of ad valorem taxes on repatriated profits or, equivalently, "melting" of goods in transit between countries. We found that the impact of reductions in conventional trade barriers on the ratio of national wages, and the "passthrough" of these reductions to domestic wages, increases with familiarity. Since in our model the volume of trade is increasing in familiarity, trade tax changes have a greater impact on wages 
when the initial volume of trade is greater, all else equal. Our model thus has implications for the effects of trade liberalization on wages, both over time and in cross-section. If familiarity is in fact increasing with time, past impacts of trade liberalization on wages may underestimate the impacts of future liberalization, at least if the liberalization involves reductions in trade taxes. ${ }^{19}$ In cross-section, our model suggests that trade liberalization with countries with which the initial volume of trade is greater, all else equal, will have greater impact on domestic wages.

It may also be possible to extend the application of our model to issues that arise in the international finance rather than the international trade literature. For example, we could reinterpret the familiarity parameter $k$ in our model as varying across sectors rather than across country pairs or over time, and apply our model to sectoral deviations from the "proportionate law of one price," christened PLOP by Engel and Rogers (forthcoming). ${ }^{20}$ In this interpretation of our model the producers become distributors, labor supplies become sectoral outputs that are exogenously supplied in a partial rather than general equilibrium framework, and changes in the exchange rate cause proportionate changes in $T$. If $\varepsilon=1$, it follows from our "convergence" result after Proposition 5 and from Proposition 7 that PLOP holds asymptotically in our model as $k$ approaches zero. The deviation from PLOP is then increasing in $k$, whether it results from "real" factors (changes in relative national outputs-Proposition 5) or "nominal" factors (changes

\footnotetext{
${ }^{19}$ We leave analysis of the interaction of informational barriers to trade with quantitative restrictions to future research. One way to handle quantitative restrictions in our model would be to allow only a subset of domestic producers who have licenses to engage in international joint ventures to match with producers abroad.

${ }^{20} \mathrm{PLOP}$ states that the percentage change in a home sector's price equals the percentage increase in the price of foreign currency plus the percentage change in the corresponding foreign sector's price.
} 
in the exchange rate reflected in changes in T-Proposition 7). As argued in Rauch (1999), $k$ is greater in differentiated product than in homogeneous product sectors in the sense that finding a profitable match with whom to engage in international commodity arbitrage is more difficult, so we can expect deviations from PLOP to be greater for the former sectors. We hope to explore these and other applications of our model in future research. 


\section{REFERENCES}

Becker, Gary S. 1957. The Economics of Discrimination (Chicago: University of Chicago).

Egan, Mary Lou and Mody, Ashoka. 1992. "Buyer-Seller Links in Export Development." World Development 20 (March): 321-334.

Engel, Charles M. and Rogers, John H. Forthcoming. "Violating the Law of One Price: Should We Make a Federal Case Out of It?" Journal of Money, Credit, and Banking.

MacDougall, G.D.A. 1960. "The Benefits and Costs of Private Investment from Abroad: A Theoretical Approach." Economic Record, Special Issue, March.

Portes, Richard and Rey, Hélène. 1999. "The Determinants of Cross-Border Equity Flows." National Bureau of Economic Research Working Paper No. 7336 (September).

Rauch, James E. 1999. "Networks Versus Markets in International Trade." Journal of International Economics 48 (June): 7-35.

Rauch, James E., and Casella, Alessandra. 1998. "Overcoming Informational Barriers to International Resource Allocation: Prices and Group Ties." National Bureau of Economic Research Working Paper No. 6628 (June).

Rodrik, Dani. 1997. Has Globalization Gone Too Far? (Washington, D. C.: Institute for International Economics).

Samuelson, Paul A. 1954. "The Transfer Problem and Transport Costs: Analysis of Effects of Trade Impediments." Economic Journal 64 (June): 264-289. 
Table 1

Numbers of Periodicals and Newsletters Devoted to International Trade and Commerce

$\begin{array}{lcccc} & \underline{1975-6} & \underline{1986-7} & \underline{1996-7} \\ \text { Ulrich's } & 334 & 431 & 1028 \\ \text { Standard } & \underline{1970} & \underline{1979-80} & \underline{1990} & \underline{1999} \\ & 300 & 384 & 418 & 1079 \\ & & \underline{1979} & \underline{1989} & \underline{1999} \\ \text { Oxbridge } & 56 & 143 & 354\end{array}$

Ulrich's = Ulrich's International Periodicals Directory: Business and Economics-International Commerce. $1975-6$ = first year for this classification.

Standard $=$ Standard Periodical Directory: International Trade.

Oxbridge $=$ Oxbridge Directory of Newsletters: International Trade $1979=$ founding year for Oxbridge. 


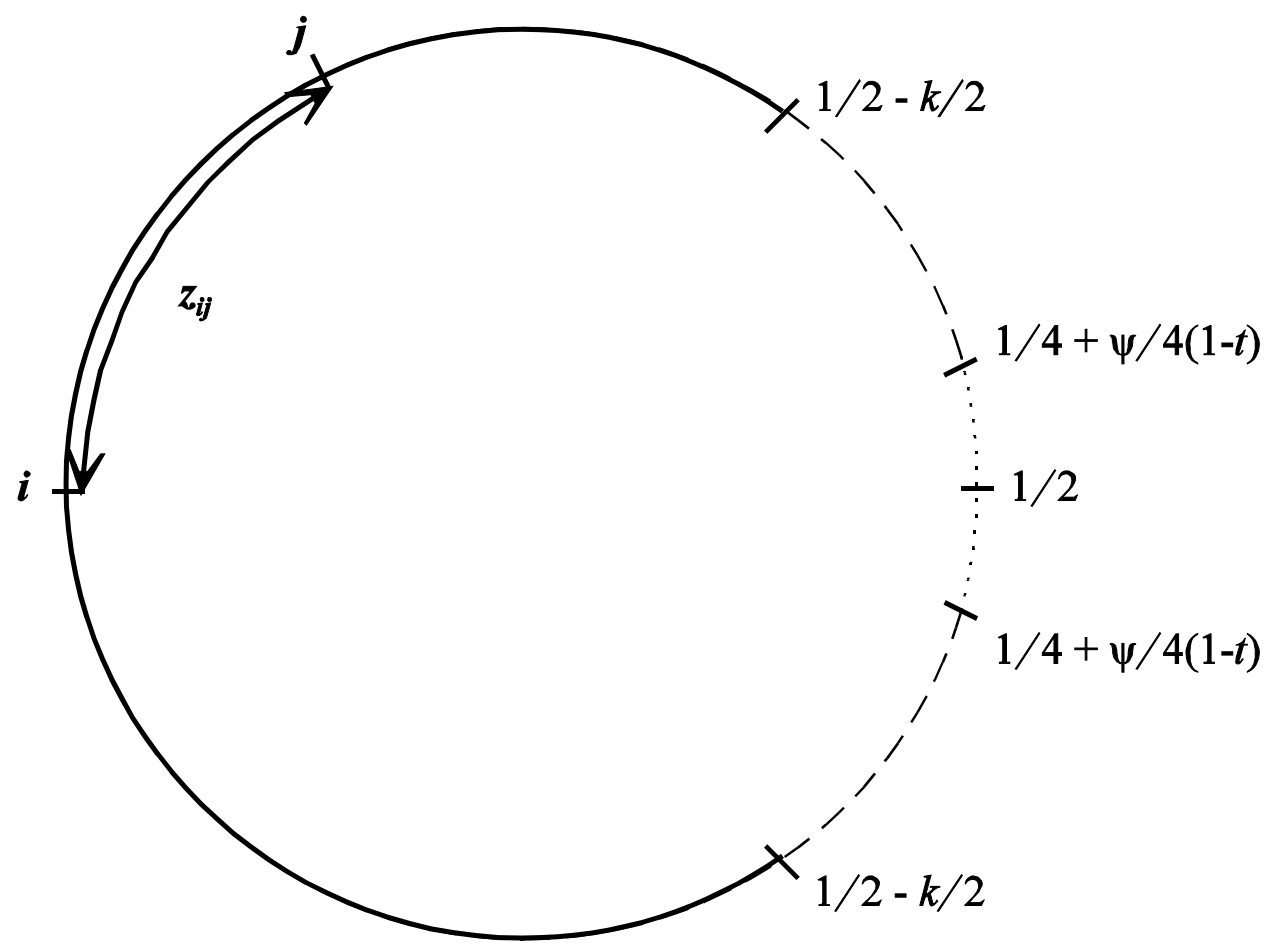

$-\ldots-\ldots-\ldots$ unsuccessful matches

successful matches

Figure 1

International matching: Distances between home producer $i$ and foreign producer $j$. 


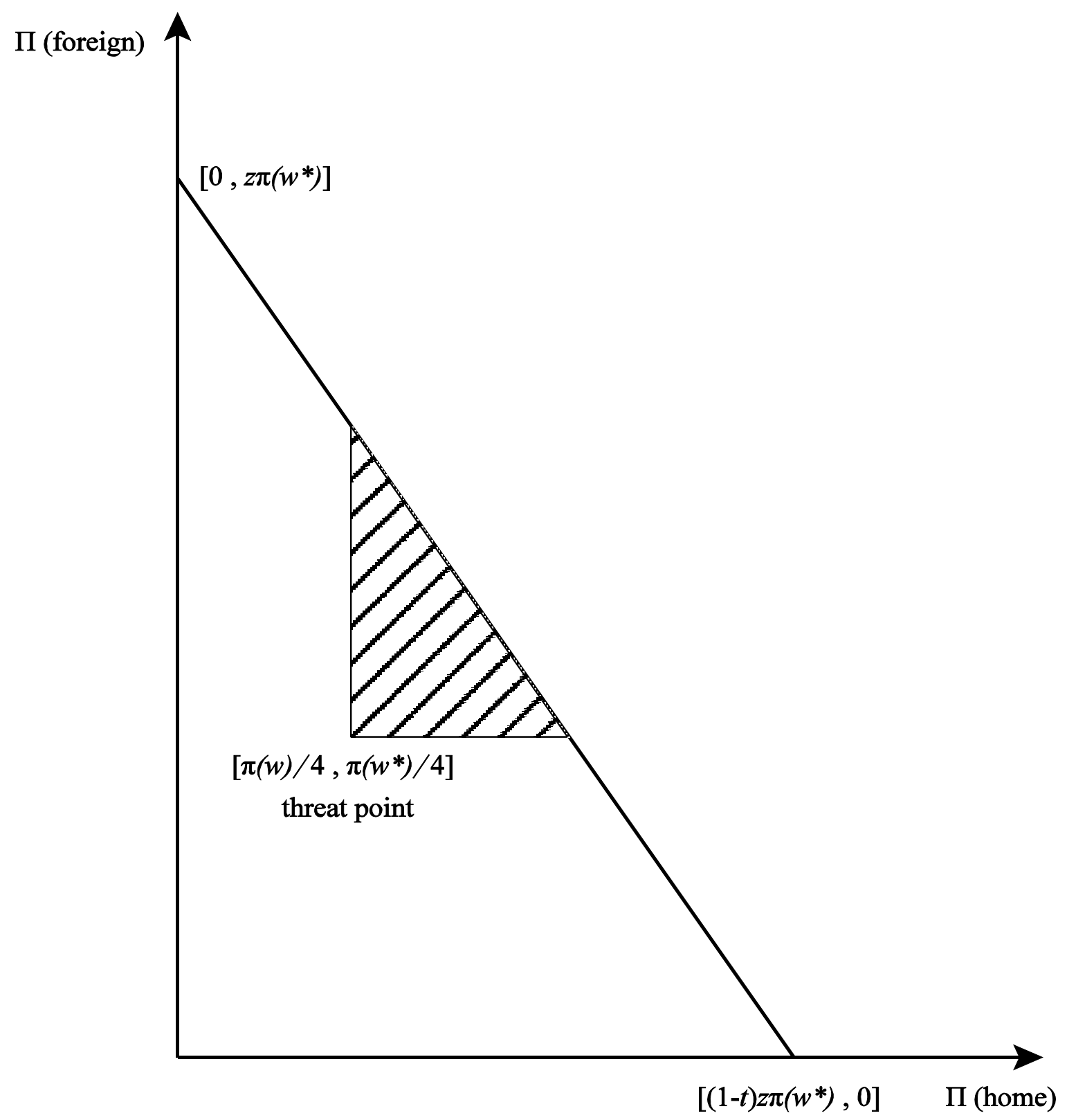

Figure 2

The bargaining problem. 


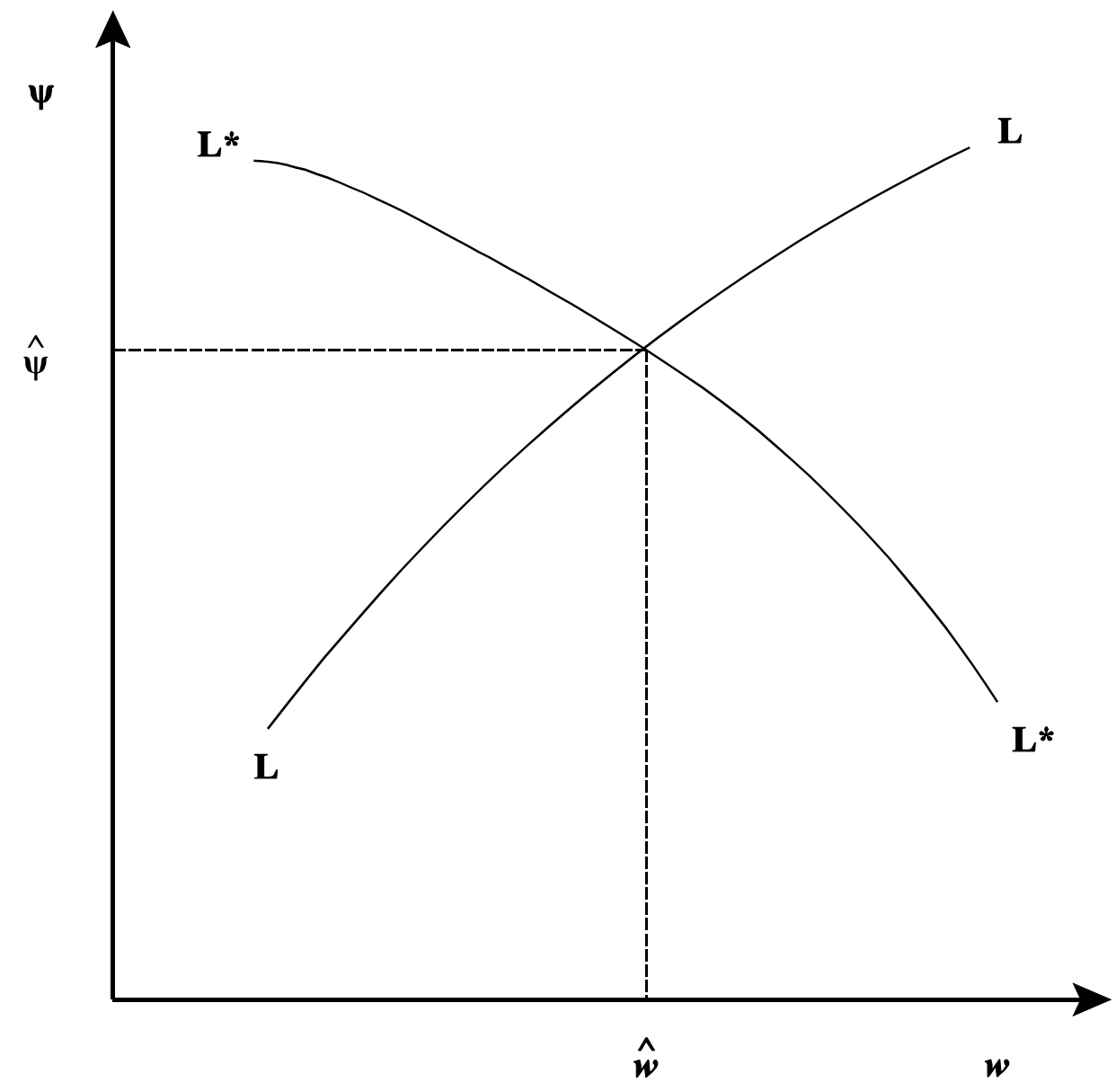

Figure 3

Determination of equilibrium wage and wage ratio. 


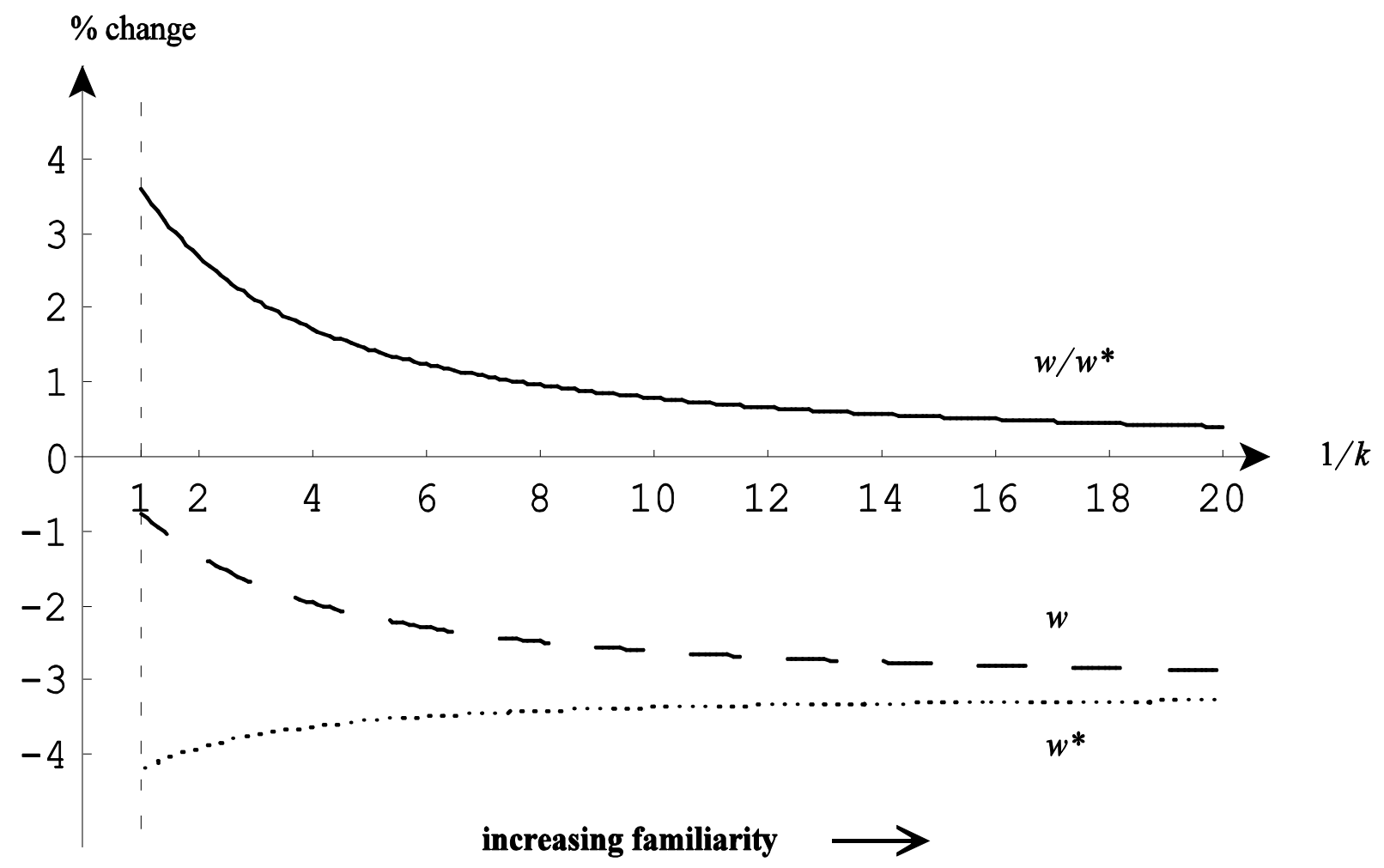

Figure 4

Wage co-movements in response to a $10 \%$ increase in foreign labor supply. 


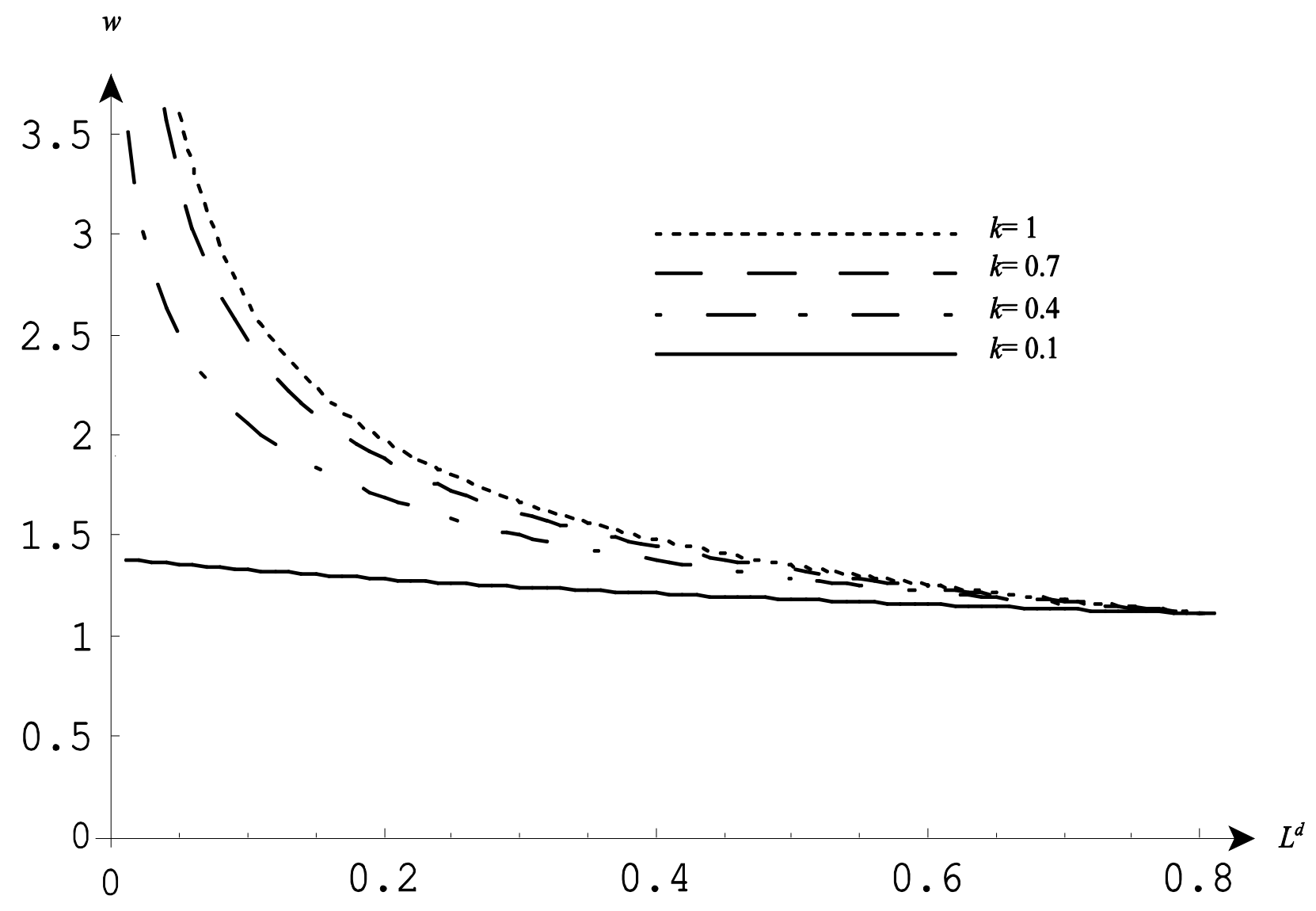

Figure 5

Changes in the home labor demand curve as familiarity increases ( $w^{*}$ fixed). 


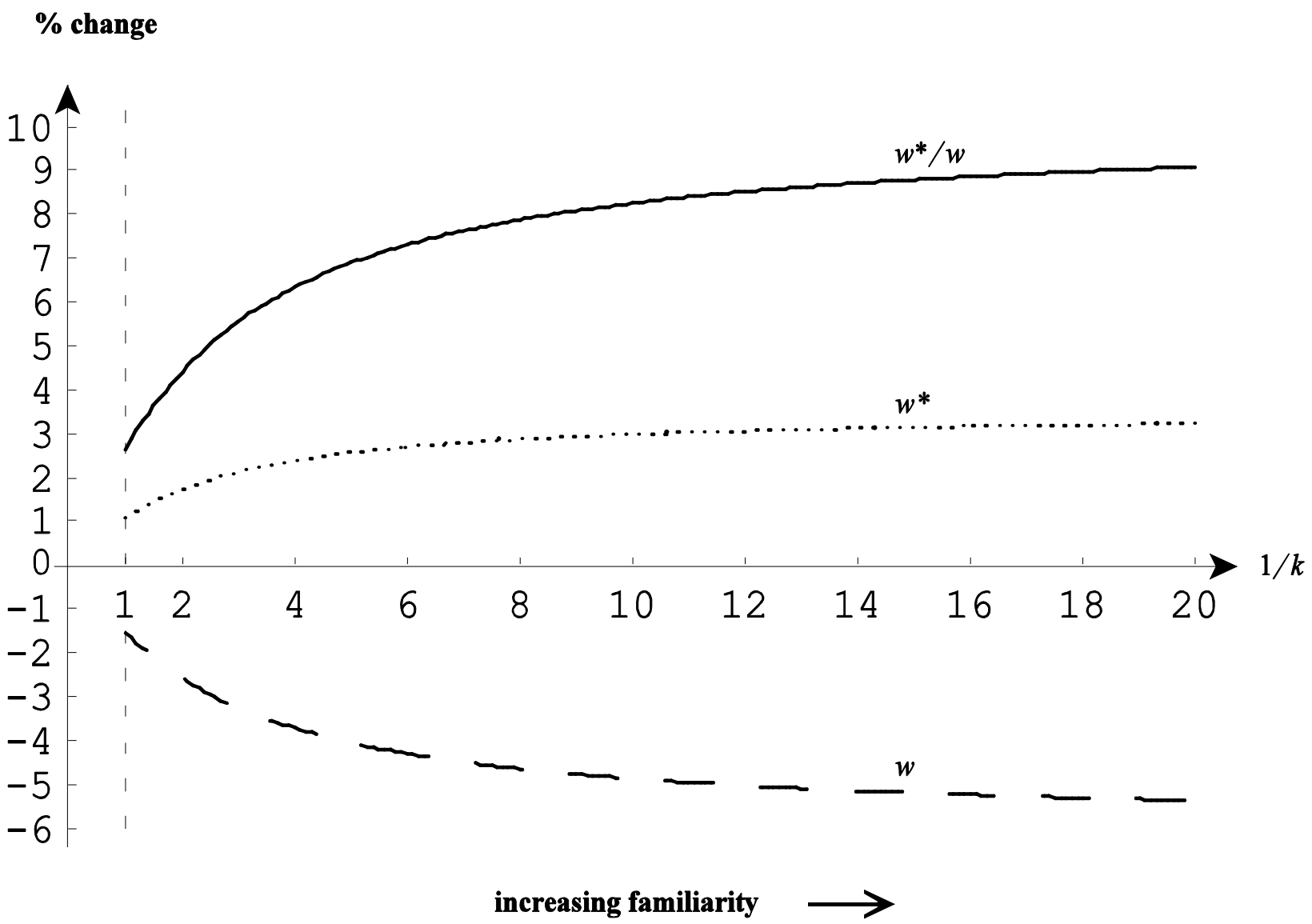

Figure 6

Relative wage response to a $10 \%$ trade liberalization $(10 \%$ increase in $T=1-t)$. 


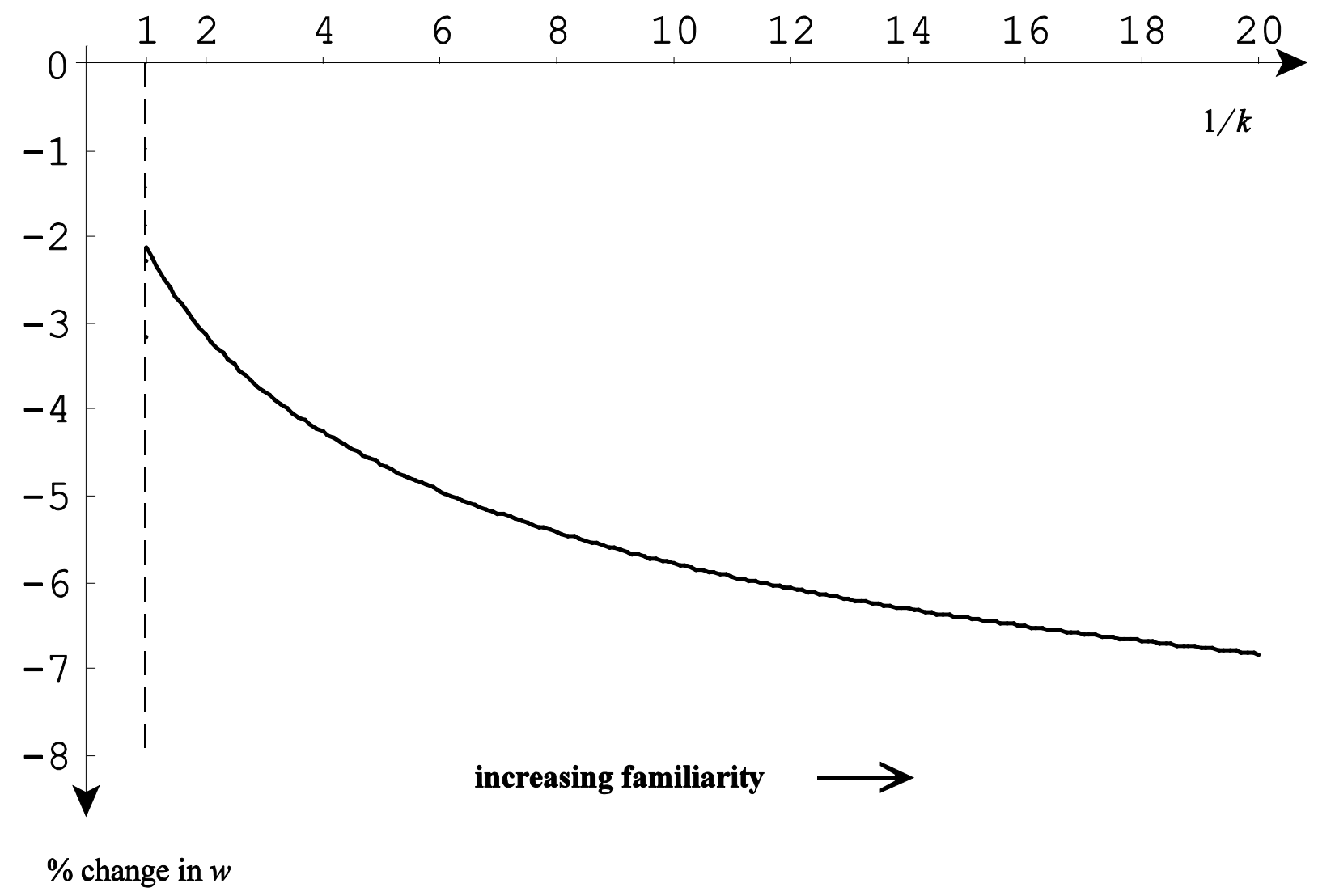

Figure 7

Pass-through of $10 \%$ trade liberalization to wages. 


\section{APPENDIX}

Proof of Proposition 7: We begin by rewriting equation (9) in a way that is closer to a simple division of equation $\left(8^{*}\right)$ into $(8)$ :

$$
\frac{1-\frac{1}{2 k}\left(1-\frac{\psi}{T}\right)}{1+\frac{1}{4 k}\left(1-\frac{\psi^{2}}{T^{2}}\right)} \psi^{1+1 / \varepsilon}=R
$$

where we have made the change of variable $T \equiv 1-t$ and used the fact that $g(\psi)=\psi^{1+1 / \varepsilon}$. It is easy to see from equation (A1) that $\psi$ must increase less than proportionately in response to an increase in $T$. If it increased proportionately the fraction on the left-hand side would remain constant and the whole left-hand side would increase, a contradiction. This argument applies $a$ fortiori to rule out a more than proportionate increase in $\psi$. It follows that $0<e_{\psi, T}<1$.

We now show that $e_{y, T}$ decreases with $k$. Let us denote the numerator and the denominator in equation (A1) by $A$ and $B$, respectively:

$$
A=1-\frac{1}{2 k}\left(1-\frac{\psi}{T}\right)=1-P,
$$

where use has been made of equation (6), and

$$
B=1+\frac{1}{4 k}\left(1-\frac{\psi^{2}}{T^{2}}\right) .
$$

Logarithmically differentiating (A1) with respect to $T$, we obtain:

$$
\frac{1}{A} \frac{\partial A}{\partial T}-\frac{1}{B} \frac{\partial B}{\partial T}+\left(1+\frac{1}{\varepsilon}\right) \frac{1}{\psi} \frac{\partial \psi}{\partial T}=0 .
$$

It is straightforward to calculate:

$$
\begin{aligned}
& \frac{\partial A}{\partial T}=-\frac{1}{2 k} \frac{\psi}{T^{2}}\left(1-e_{\psi, T}\right), \text { and } \\
& \frac{\partial B}{\partial T}=\frac{1}{2 k} \frac{\psi^{2}}{T^{3}}\left(1-e_{\psi, T}\right) .
\end{aligned}
$$

Note that the first two terms in equation (A2) are both negative. 
Suppose now that when $k$ increases, $\left(1-e_{\psi, T}\right)$ is either constant or decreases, implying that $e_{\psi, T}$ does not decrease. Because $\psi$ is decreasing in $k$, we can deduce that:

i) $\partial A / \partial T$ decreases (in absolute value) with $k$;

ii) $A$ increases with $k$, because the Lemma tells us that $P$ decreases with $k$; and

iii) $\frac{1}{B} \frac{\partial B}{\partial T}=\frac{2\left(1-e_{\psi, T}\right) \psi^{2} / T^{3}}{4 k+1-\psi^{2} / T^{2}}$ decreases with $k$.

These three results imply that the last term in equation (A2), which is positive, also decreases with $k$. But that term is simply proportional to $e_{\psi, T}$, so we arrive at a contradiction. Therefore it must be that $\left(1-e_{\psi /, T}\right)$ increases and $e_{\psi, T}$ decreases with $k$, as we wished to prove.

Let us now prove that $e_{y, T} \rightarrow 1$ as $k \rightarrow 0$. If this is not true, $\left(1-e_{y /, T}\right)$ does not tend to zero as $k \rightarrow 0$. Recalling that $\psi \rightarrow T$ when $k \rightarrow 0$, this implies that both

$\frac{1}{A} \frac{\partial A}{\partial T}=-\frac{\left(1-e_{\psi, T}\right) \psi / T^{2}}{2 k-1+\psi / T}$ and $-(\partial B / \partial T) / B$ go to $-\infty$ as $k \rightarrow 0$. It then follows from equation (A2) that $e_{\psi, T} \rightarrow+\infty$, which contradicts $e_{\psi, T}<1$, thus establishing the result. 